\title{
Rita Levi-Montalcini: Presence in The Absence
}

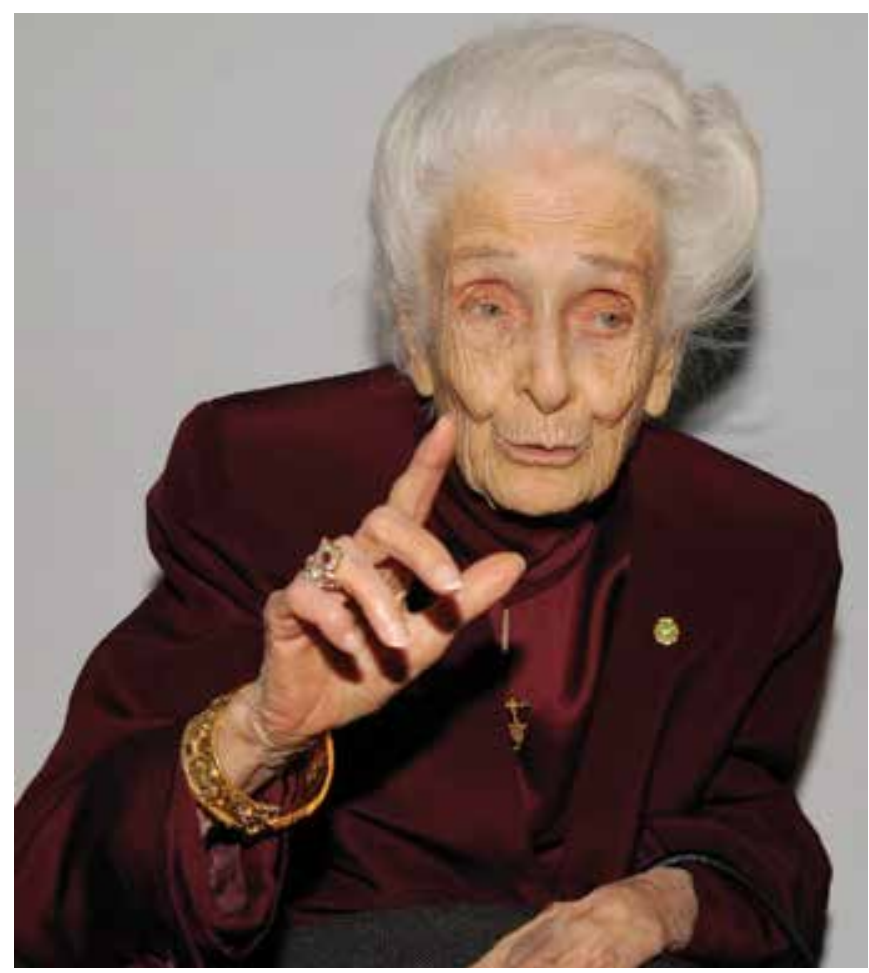

Photo by Giuseppe Nicoloro with permission*

Professor Rita Levi-Montalcini, the 1986 Nobel Prize winner in Physiology or Medicine for the discovery of nerve growth factor (NGF), died Sunday, 30 December 2012, at her home in Rome, Italy. She was 103 years old.

Her amazing journey in Eureka-land started from her "private laboratory" in Turin which she named Robinson Crusoe, later on through Viktor Hamburger's Department of Zoology of Washington University in St Louis, MO and in Herta Mayer's Tissue Culture Laboratory in Rio de Janeiro to Rome, Italy where in 1962, Levi-Montalcini became Director of the Institute of Cell Biology, splitting her time between St Louis and Rome until 1977.

Levi-Montalcini's NGF provided a conceptual framework for the formulation of the neurotrophic hypothesis: particular neuronal types require trophic ("nutritional") factor(s) for neurite growth and neurotransmitter production for proper function and survival. Her data on the prototype neurotrophic factor, NGF, triggered an unprecedented search for a family of related proteins now commonly called neurotrophins.

More importantly, Levi-Montalcini's NGF determined a new concept of biology, that cells require specific protein signals for differentiation and survival, that is, the general theory of cell growth factors. All this resulted in the discovery of hundreds of growth factors that affect almost all facets of cell biology. In analogy with Mendelevium (Md), Einsteinium (Es) and Fermium (Fm) in Dimitri Mendeleev's Periodic Table of chemical elements, we may now introduce NGF as Montalcinium (Mt) in the Periodic Table of biomolecules.

Her centennial life created the scientific bridge between two millenia, a path followed by many generations. This is the guarantee of her "presence in the absence".

\author{
Luigi Aloe ${ }^{1}$, George N. Chaldakov ${ }^{2}$ \\ ${ }^{1}$ Institute of Cell Biology and Neurobiology, National \\ Research Council (CNR), Rome, Italy \\ 'Laboratory of Cell Biology, Medical University, \\ Varna, Bulgaria
}

